\title{
SATISFAÇÃO E ENGAJAMENTO DE VISITANTES À FESTIVAIS: ANÁLISE EMPÍRICA DE UMA OKTOBERFEST ${ }^{1}$
}

\author{
iD Camila Belli Kraus \\ Doutoranda em Ciências Contábeis e Administração. \\ Universidade Regional de Blumenau (FURB), Blumenau, Santa Catarina, Brasil \\ kmilabk@gmail.com \\ Thamires Foletto Fiuza \\ Doutoranda em Turismo e Hotelaria \\ Universidade do Vale do Itajaí (UNIVALI), Balneário Camboriú, Santa Catarina, Brasi \\ thamiresf.fiuza@gmail.com \\ Fabricia Durieux Zucco \\ Doutora em Administração \\ fabriciazucco@hotmail.com
}

Resumo Prof. Do PPGTH da UNIVALI e Dep. De Comunicação da FURB, Balneário Camboriú e Blumenau, Santa Catarina, Brasil

Objetivo do estudo: Analisar a relação entre a satisfação e o engajamento online dos visitantes da 34 Oktoberfest de Blumenau, Santa Catarina, Brasil, realizada no ano de 2017.

Metodologia/abordagem: Realizou-se uma pesquisa exploratória, documental e descritiva, com abordagem quantitativa, por meio de um levantamento survey com questionário, aplicado durante o mês de outubro de 2017 na Oktoberfest Blumenau, o qual resultou em 215 questionários válidos.

Originalidade/Relevância: O uso de festivais como promotores do turismo em destinos vem sendo massivamente utilizado, porém, com seu crescimento, percebeu-se a necessidade de encontrar estratégias para manter o visitante satisfeito e engajado com a sua realização, buscando assim, a manutenção de sua atratividade e intenção de revisitar tal evento. A Oktoberfest é o principal festival cultural alemão realizado em todo o país, e Blumenau possui a maior edição do Brasil em número de público. Assim, evidencia-se a necessidade de avaliar como o visitante está percebendo a realização do festival e o quanto sente-se engajado com este, buscando a manutenção da qualidade e valorização da cultura típica alemã demonstrada através da Oktoberfest. Principais resultados: Entre os principais achados, destaca-se que as mulheres ficaram mais satisfeitas com a dimensão Tangibilidade, enquanto os homens com a dimensão Empatia. Foi possível identificar ainda, que a satisfação do visitante não tem relação com o engajamento online.

Contribuições teóricas/metodológicas: $\mathrm{O}$ estudo contribui com a literatura acadêmica através do avanço em pesquisas relacionadas a festivais e engajamento, principalmente através do uso da Oktoberfest como objeto de estudo. Tal festival vem sendo utilizado como produto turístico em todo o mundo, porém, pesquisas que identifiquem como este vem se desenvolvendo e se de fato vem representando a cultura de forma satisfatória ainda não alcançaram um espaço significativo no meio acadêmico.

Contribuições sociais / para a gestão: Os resultados aqui apresentados fornecem importantes resultados para a gestão e marketing não apenas da Oktoberfest de Blumenau, mas também para os demais eventos culturais, onde evidenciam que existem diferenças significativas em relação aos fatores pessoais e a sua percepção de engajamento e satisfação.

Palavras-chave: Festivais. Engajamento. Satisfação. Oktoberfest.

\section{Cite como}

American Psychological Association (APA)

Kraus, C. B., Fiuza, T. F., Zucco, F. D., \& Quadros, C. M. B. (2020). Satisfação e engajamento de visitantes à festivais: análise empírica de uma Oktoberfest. PODIUM Sport, Leisure and Tourism Review, São Paulo, 9(2), 308-336. https://doi.org/10.5585/podium.v9i2.14683.

\footnotetext{
${ }^{1}$ O presente trabalho foi realizado com apoio da Coordenação de Aperfeiçoamento de Pessoal de Nível Superior - Brasil (CAPES) - Código de Financiamento 001.
} 


\section{SATISFACTION AND ENGAGEMENT OF FESTIVAL VISITORS: EMPIRICAL ANALYSIS OF AN OKTOBERFEST}

Objective of the study: To analyze the relationship between satisfaction and online engagement of visitors to the 34th Oktoberfest in Blumenau, Santa Catarina, Brazil, held in 2017.

Methodology/approach: An exploratory, documentary, and descriptive research was carried out, with a quantitative approach, through a survey with a questionnaire, applied during the month of October 2017 at Oktoberfest Blumenau, which resulted in 215 valid questionnaires.

Originality/Relevance: The use of festivals as promoters of tourism in destinations has been massively used. However, with its growth, there was a need to find strategies to keep the visitors satisfied and engaged with its realization. Thus, seeking to maintain of its attractiveness and intention to revisit such an event. Oktoberfest is the main German cultural festival held across the country, and Blumenau has the largest edition in Brazil in number of audiences. Therefore, it is evident the need to assess how the visitor is perceiving the festival and how much she/he feels engaged with it, seeking to maintain the quality and appreciation of the typical German culture demonstrated through the Oktoberfest.

Main results: Among the main findings, it is highlighted that women were more satisfied with the Tangibility dimension, while men with the Empathy dimension. It was also possible to identify that visitor's satisfaction is not related to online engagement.

Theoretical/methodological contributions: The study contributes to the academic literature by advancing research related to festivals and engagement, mainly through the use of Oktoberfest as an object of study. This festival has been used as a tourist product all over the world, however, researches that identify how it has been developing and whether it is in fact representing culture in a satisfactory way has not reached yet a significant space in the academic environment.

Social/management contributions: The results presented here provide important results for the management and marketing not only of Blumenau's Oktoberfest, but also for other cultural events, where it shows that there are significant differences in relation to personal factors and their perception of engagement and satisfaction.

Keywords: Festivals. Engagement. Satisfaction. Oktoberfest.

\section{SATISFACCIÓN Y COMPROMISO DE LOS VISITANTES A LOS FESTIVALES: ANÁLISIS EMPÍRICO DE UN OKTOBERFEST}

Objetivo del estudio: analizar la relación entre la satisfacción y el compromiso en línea de los visitantes del $34^{\circ}$ Oktoberfest en Blumenau, Santa Catarina, Brasil, celebrado en 2017.

Metodología/enfoque: Se realizó una investigación exploratoria, documental y descriptiva, con un enfoque cuantitativo, a través de una encuesta con un cuestionario, aplicada durante el mes de octubre de 2017 en el Oktoberfest Blumenau, que dio como resultado 215 cuestionarios válidos.

Originalidad/Relevancia: El uso de festivales como promotores del turismo en los destinos se ha utilizado de forma masiva, sin embargo, con su crecimiento, se hizo realidad la necesidad de encontrar estrategias para mantener al visitante satisfecho y comprometido con su realización, buscando así el mantenimiento de su atractivo e intención de volver a visitar tal evento. Oktoberfest es el principal festival cultural alemán celebrado en todo el país, y Blumenau tiene la mayor edición de Brasil en 
número de audiencias. Por lo tanto, es necesario evaluar cómo el visitante percibe el festival y cuánto se siente comprometido con él, buscando mantener la calidad y la apreciación de la cultura típica alemana demostrada a través del Oktoberfest.

Resultados principales: Entre los principales hallazgos, se destaca que las mujeres estaban más satisfechas con la dimensión Tangibilidad, mientras que los hombres con la dimensión Empatía. También fue posible identificar que la satisfacción del visitante no está relacionada con la participación en línea.

Contribuciones teóricas/metodológicas: el estudio contribuye a la literatura académica mediante el avance de la investigación relacionada con festivales y participación, principalmente a través del uso de Oktoberfest como objeto de estudio. Tal festival se ha utilizado como producto turístico en todo el mundo, sin embargo, la investigación que identifica cómo se ha desarrollado y si de hecho ha representado la cultura de manera satisfactoria aún no ha alcanzado un espacio significativo en el entorno académico.

Contribuciones sociales/de gestión: Los resultados presentados aquí proporcionan resultados importantes para la gestión y comercialización no solo del Oktoberfest de Blumaneu, sino también para otros eventos culturales, donde muestra que existen diferencias significativas en relación con los factores personales y su percepción de Compromiso y satisfacción.

Palabras clave: Festivales. Compromiso. Satisfacción. Oktoberfest.

\section{Introdução}

Os festivais foram criados com o intuito de promover e valorizar a cultura dos povos, através da manifestação festiva de ritos, hábitos, cultura e gastronomia local (Egresi \& Kara, 2014; Moretti, Zucco, \& Pozo, 2016). Santos Zucco e Kraus (2015) defendem que os festivais são celebrações culturais que ocupam um significativo espaço na identidade da comunidade. A importância destes pode ser atribuída não apenas à preservação da cultura local e demonstração da sua herança histórica, tradições e etnicidade, mas também devido à sua importância atração de turistas ao destino (Tanford \& Jung, 2017).

Dentro de tal sentido, Tontini, Branco, Brandt, Ronchi, Oliveira e Zanchett (2018) também defendem a importância de festivais para o turismo. Para os autores (2018), a possibilidade (e necessidade) de valorização da cultura, aliado a constante necessidade de novos produtos turísticos têm fortalecido a união entre tais eventos e a atividade turística. Já Felsenstein e Fleischer (2003) demonstram três razões do crescimento de festivais regionais para o desenvolvimento do turismo.

O primeiro estava relacionado a capacidade deste em ampliar a demanda do turismo local; o segundo consistia possibilidade da recriação de uma imagem de lugar, através do uso de festivais; e por fim, a terceira estava diretamente relacionada ao posicionamento estratégico 
Kraus, C. B., Fiuza, T. F., Zucco, F. D., \& Quadros, C. M. B. (2020). Satisfação e engajamento de visitantes à festivais: análise empírica de uma Oktoberfest

de tal tipologia de evento no calendário turístico, o qual possibilitaria a extensão da temporada de turismo (Felsenstein \& Fleischer, 2003).

Percebe-se assim, que os festivais são vistos como uma importante ferramenta de geração de benefícios sociais e econômicos para as comunidades agindo como um importante impulsionador na geração de emprego e renda para o território e ainda, fomentador da coesão social (Moyano, Lengler, Angnes, \& Sampaio, 2015; Yoon, Lee \& Lee, 2010). Egresi e Kara (2014) atribuem estes benefícios ao rápido crescimento da diversidade e quantidade de festivais realizados nos últimos anos por destinos.

Com o crescimento do número de festivais, muitos estudos também surgiram, a fim de identificar as diferentes variáveis envolvidas na realização destes nas comunidades (Kim, Duncan, \& Chung, 2015). A maioria das pesquisas relacionadas a temática, tem como objetivo identificar a motivação dos visitantes, a lealdade e a satisfação dos frequentadores (Yoon et al., 2010) e mais recentemente, a relação entre os festivais e a comunidade local, através da avaliação dos impactos da realização destas nos destinos (Andersson, Armbrecht, \& Lundberg, 2017).

Small (2007) defende a realização de diversos estudos semelhantes relacionados a temática, visto que cada festival é único e possui características próprias que influenciam os resultados. Dentro desta mesma perspectiva, Mcdowall, Lillywhite e Simonsen (2014) asseguram que as pesquisas empíricas relacionadas a festivais podem possuir similaridades, todavia, dificilmente apresentarão os mesmos resultados, devido as distintas variáveis que influenciam a realização destes nos destinos.

Na literatura do turismo, tem-se encontrado que a avaliação de aspectos capazes de influenciar a participação dos visitantes em festivais, bem como verificar os níveis de satisfação e o seu desempenho, é uma questão fundamental a ser analisada (Tontini et al., 2018). Por outro lado, Yoon et al. (2010) defendem que apenas entender os motivos dos visitantes é insuficiente para garantir a satisfação e a fidelidade destes. A compreensão de motivos também precisa ser fatorada em construção de qualidades atraentes do festival e relacionar tais achados com o comportamento do visitante e o seu engajamento com o evento (Silva \& Gonçalves, 2015, Yoon et al., 2010).

Destaca-se que a satisfação e o engajamento com festivais, para Sohn, Lee e Yoon (2016) é uma consequência de um conjunto de fatores, os quais são afetados diretamente pela experiencia do visitante. Tal experiência intrínseca e extrínseca, para Tanford e Jung (2017) 
Kraus, C. B., Fiuza, T. F., Zucco, F. D., \& Quadros, C. M. B. (2020). Satisfação e engajamento de visitantes à festivais: análise empírica de uma Oktoberfest

tende a afetar o senso de valor, intenção de revisitar, a satisfação, o comportamento subsequente e o engajamento do participante.

Chen, Lee e Lin (2012) afirmam que a percepção relacionada a qualidade do festival é uma questão fundamental para garantir aos visitantes a satisfação, engajamento e a repetição de visitas. Tais fatores são capazes de ampliar o interesse também de novos participantes, ampliando ainda a promoção de novos negócios e benefícios econômicos para o destino receptor. Tontini et al. (2018), Moyano et al. (2015) e ainda Zucco, Magalhães e Moretti (2010) enfatizam o potencial da Oktoberfest para tal contexto de prospecção de visitantes e consequente benefício para a comunidade. Segundo os autores, festivais com as características da Oktoberfest geram experiencias únicas aos visitantes.

A experiência derivada do comparecimento à Oktoberfest ou a outros festivais é um fenômeno complexo que afeta a satisfação, a propaganda boca a boca positiva e a lealdade (Manthiou, Lee, Tang \& Chiang, 2014). Apesar de tal exposto, Harrington, Von-Freyberg, Ottenbacher e Schmidt (2017) afirmam que a Oktoberfest é atualmente um festival internacional com uma longa história, forte reconhecimento de nome e um importante fator econômico do turismo por si só, porém, esta ainda é considerada parte de uma área crescente, mas sob pesquisa ainda incipiente, de turismo de cerveja e das variáveis de sucesso e reconhecimento de festivais. O estudo de Harrington et al. (2017) evidenciou que no contexto alemão, a cultura tradicional e a atmosfera de festa eram elementos básicos previstos. Adicionalmente, uma pesquisa realizada por Fiuza, Zucco, Añaña e Sohn (2020) percebeu que em relação a Oktoberfest de Santa Cruz do Sul (Rio Grande do Sul, Brasil) existiam algumas cruciais de avaliação entre os residentes de diferentes sexos ou grupos étnicos e diferentes idades ou tempos de residência no município.

Desta forma, evidencia-se as diversas variáveis que devem ser analisadas em relação a um festival tão complexo, relevante e utilizado em várias cidades do mundo como uma ferramenta de valorização da cultura alemã. Percebe-se a importância de avaliar qual o grau de satisfação e engajamento de visitantes da Oktoberfest, a fim de compreender a dinâmica de tal evento e ainda, a manutenção deste como produto turístico de valorização de uma cultura. Assim, optou-se por realizar um estudo abordando a maior festa alemã das Américas e a principal Oktoberfest brasileira, que é realizada em Blumenau, Santa Catarina. O festival acontece no mês de outubro desde 1984 e atraiu 568.027 visitantes em 2017. Blumenau além 
Kraus, C. B., Fiuza, T. F., Zucco, F. D., \& Quadros, C. M. B. (2020). Satisfação e engajamento de visitantes à festivais: análise empírica de uma Oktoberfest

de ser internacionalmente conhecida pela Oktoberfest, é considerada o principal polo econômico e turístico do Vale do Itajaí (Blumenau, 2017).

Assim, a presente pesquisa tem como objetivo analisar a relação entre a satisfação e o engajamento online dos visitantes da $34^{\text {a }}$ Oktoberfest de Blumenau, Santa Catarina, Brasil, realizada no ano de 2017. Para alcançar o objetivo proposto, o estudo foi estruturado em seis seções. A primeira apresentou a introdução abordando a importância da temática e definição do objetivo. Posteriormente, tem-se o referencial teórico onde são apresentados os principais estudos relacionados a temática, os quais fundamentam a realização do presente trabalho. A metodologia é apresentada na terceira seção, através da apresentação da caracterização da pesquisa, instrumento utilizado e aplicação da coleta de dados e as análises utilizadas na obtenção dos resultados. Estes, são apresentados na quarta seção, bem como as suas discussões. Nas considerações finais (quinta seção) são enfatizados os principais resultados da pesquisa, e, por fim, a sexta e última seção apresenta as referencias utilizadas na construção do artigo.

\section{Satisfação e engajamento em festivais}

Não há dúvidas em relação a importância do turismo de eventos no contexto da atividade em nível mundial. Dentro do setor, os festivais vêm alcançando um importante espaço dentro das comunidades, sendo uma possibilidade de entretenimento e valorização da cultura local e ainda, um relevante produto turístico para o destino (Small, 2007). Tal modalidade de evento, segundo Tanford e Jung (2017) proporcionam as comunidades locais uma maneira de celebrar as suas tradições culturais únicas e ainda, possui um "bônus" por atrair turistas para a comunidade.

Os festivais unem ao mesmo tempo as paisagens com o estilo de vida de forma simples e complexa, introduzindo as pessoas em espaços estáticos, que por sua vez, tornam-se animados. Frequentemente, há um incentivo para que as pessoas continuem utilizando esses espaços após os festivais. O fornecimento de estrutura durável torna bastante atrativo para investimentos comunitários em eventos. Acabam se tornando atrativos para a comunidade local porque estão em busca de assuntos relativos a um modelo cívico, orgulho e identidade, patrimônio, conservação, renovação urbana, geração de emprego, além do investimento e desenvolvimento econômico (Robertson, Yeoman \& Ali-knight, 2006). 
Festivais são uma organização de um evento específico dentro do domínio cultural de uma localidade, expressando uma contribuição significativa para cultura local, e se destacando em termos de originalidade ou inovação, e ainda, implicando certo nível de organização, juntamente com uma duração mínima e certa estabilidade, bem como a frequência ao longo do tempo na sua organização (Herrero, Sanz, Bedate \& del Barrio, 2012) Desta maneira, a oportunidade de troca de experiências e informações proporcionadas pela realização de festivais pode auxiliar na concepção de um senso de valor e crença (por indivíduos) na comunidade (Esu, Arrey, Basil \& Eyo, 2011). A construção da imagem de um destino é um dos papéis mais importantes dos festivais, pois segundo Deng, Li e Shen (2013), festivais e eventos podem moldar a imagem da cidade, região ou país que os sediam e com isso, instigar uma percepção favorável como destino potencial de viagem.

Para Getz e Page (2016) as principais razões de visitar um festival são o entretenimento, diversão, socialização, aprendizagens e motivações para fazer algo novo. Todavia, deve-se salientar a motivação cultural como fator de motivação a visitação destes. Os festivais possuem uma dimensão fortemente coletiva, a qual é capaz de promover uma motivação para frequentálo. Normalmente, os visitantes buscam a expressão de crenças, celebração da identidade e confirmação da estrutura social e cultural local, através do fortalecimento dos sistemas de valores da comunidade (Kim et al., 2015).

Tontini et al., (2018) também defendem esta perspectiva ao afirmar que os festivais são uma oferta de serviços, os quais, embora compreendam atributos tangíveis (como comida, bebida e outros), ele consiste em um serviço formado por experiências intangíveis durante um tempo limitado. Levando em consideração o exposto, destaca-se que distintos aspectos de um festival são capazes de impactar na experiência do visitante, o qual, se não vivenciar o "cenário" esperado, tende a diminuir o seu nível de satisfação e intenção de revisitar (Getz \& Page, 2016, Sohn, Lee, \& Yoon, 2016). Tal exposto é comprovado no estudo de Harrington et al. (2017) o qual descobriu que o contexto alemão, a cultura tradicional e a atmosfera de festa eram elementos básicos esperado pelos visitantes da Oktoberfest de Munique, e que estes influenciavam diretamente na satisfação em visitar o evento.

A complexidade apresentada na relação entre festivais, comunidade local e o turismo fez com que a temática fosse emergente na literatura acadêmica. Kim et al. (2015) defendem que com o crescente número de festivais realizados em destinos ao redor do mundo a cada ano, torna-se crítico para os investigadores, organizadores e detentores do conhecimento 
Kraus, C. B., Fiuza, T. F., Zucco, F. D., \& Quadros, C. M. B. (2020). Satisfação e engajamento de visitantes à festivais: análise empírica de uma Oktoberfest

compreender melhor os comportamentos dos participantes. Neste sentido, Christou, Sharpley e Farmaki (2018) ainda acrescentam que as descobertas acadêmicas relacionadas a festivais podem fornecer aos organizadores importantes informações práticas para melhorar o planejamento e promoção destes buscando atrair uma maior parcela de novos visitantes e ainda, reter os antigos.

Os estudos relacionados a temática, têm demonstrado distintos resultados e salientado ainda mais a profunda relação entre as peculiaridades da cultura local e os festivais. Kim et al., (2015) reforçam em seu estudo que os primeiros trabalhos acerca de festivais possuíam como objetivo identificar a motivação dos turistas e residentes em visitar (ou não) tais eventos. Todavia, com o aprofundamento e consolidação desta tipologia, apenas entender os motivos dos visitantes tornou-se insuficiente para garantir a satisfação e a fidelidade deste. Para Woosnam e Aleshinloye (2018) a compreensão de motivos também precisa ser fatorada em construção qualidades atraentes do festival e compreensão do fluxo do comportamento do visitante (como a satisfação, engajamento e lealdade).

Choo, Ahn e Petrick (2016) abordam a satisfação como uma resposta afetiva influenciada pelos atributos de qualidade experimentados pelos visitantes. A satisfação é determinada em parte pela recepção, mas também pelas informações disponíveis ao consumidor, sendo as experiências anteriores (pessoais e de terceiros) as mais importantes fontes de informação (Moretti, Silva, Pinotti, \& Zucco, 2016; Silva \& Gonçalves, 2015). A importância da satisfação no contexto de festivais é abordada por Sohn et al. (2016), os quais afirmam que esta é um conceito considerado importante no campo do marketing e do comportamento do consumidor, sendo essencial na percepção da qualidade do festival e ainda, um dos principais influenciadores da intenção de revisitar o evento.

Inicialmente, os estudos buscavam principalmente a desconfirmação da expectativa, através da avaliação sobre desempenho de produto. Após meados dos anos de 1980 as pesquisas foram expandidas com a inclusão do conhecimento sobre a satisfação do serviço, promovido principalmente pelo surgimento do SERVQUAL proposto por Parasuraman, Zeithaml e Berry (1988). A satisfação do cliente passa então a ser baseada na qualidade de serviço, que envolvem cinco dimensões a fim de originar a satisfação do cliente, sendo: a) tangibilidade; b) confiabilidade; c) atendimento; d) segurança; e) empatia (Parasuraman, Zeithaml \& Berry, 1991). Com o intuito de aprofundar o conhecimento sobre a percepção dos serviços em festivais sob a ótica da hospitalidade, Moretti et al., (2016), utilizaram a escala SERVQUAL como base, 
Kraus, C. B., Fiuza, T. F., Zucco, F. D., \& Quadros, C. M. B. (2020). Satisfação e engajamento de visitantes à festivais: análise empírica de uma Oktoberfest

essa escala ainda não havia sido aplicada nessa área de estudo. Buscaram ainda, estabelecer uma nova abordagem para a satisfação de turistas de festivais. Portanto, avaliaram as Oktoberfest de Blumenau (Brasil) e Munique (Alemanha), sob a percepção dos visitantes desses festivais.

Atualmente, diversos estudos vêm surgindo, buscando avaliar a satisfação dos visitantes com festivais. Dentre tais pesquisa, pode-se citar a de Choo et al. (2016), que ao analisar a qualidade do Nonsan Strawberry Festival (Coréia) e o comportamento do consumidor, perceberam que a satisfação foi o maior preditor de intenção de revisitar festivais, seguida pela identidade social, normas subjetivas e de grupo. Os autores (2016) perceberam ainda que os maiores níveis de satisfação estavam relacionados ao programa do festival, o ambiente e as lembranças promovidas por este. No mesmo sentido, o estudo formulado por Sohn et al. (2016) verificou que a avaliação do festival influencia na satisfação geral e na intenção comportamental. A satisfação é capaz de influenciar na recomendação aos outros e também, na motivação em revisitar o festival. Todavia, os resultados de Sohn et al. (2016) ainda demonstraram que o aumento da percepção negativa do festival não foi capaz de reduzir o nível de satisfação ou uma futura intenção comportamental, ou seja, os visitantes são capazes de suportar algumas percepções negativas sem que estas influenciem nas suas intenções futuras.

A satisfação também foi a temática central do estudo formulado por Kim et al. (2015) os quais buscaram segmentar os participantes de um festival com base no envolvimento, valor percebido, satisfação e intenção de revisitá-lo. O estudo demonstrou que os participantes locais demonstraram maior envolvimento, satisfação e intenção de revisitar do que aqueles oriundos de destinos distantes. $\mathrm{O}$ achado reforça as características de festivais, os quais foram criados buscando promover e valorizar culturas locais, logo, a tendência é que os residentes possuam maior envolvimento e satisfação com este.

As dimensões da qualidade na satisfação geral dos visitantes de festivais foram analisadas por Tontini et al. (2018). Os resultados demonstraram que os participantes mais jovens e que visitam o festival com maior frequência possuem maior satisfação com estes eventos. As dimensões com maiores índices de satisfação dos frequentadores foram aquelas relacionadas à novidade do festival, ambiente físico, variedade de comidas típicas, interação da comunidade local com os visitantes, preço e valor, segurança do festival, tráfego e acesso a cidade, tempo nas filas e atributos típicos. Os resultados encontrados pelos autores corroboram o exposto por Moretti et al. (2016) os quais defendem que os consumidores geralmente julgam 
a qualidade de um serviço com base numa grande variedade de elementos intrínsecos e extrínsecos que, separadamente ou combinados, fornecem as bases para a percepção da satisfação com o festival. Tontini et al. (2018) também defendem essa perspectiva, ao afirmar que os aspectos distintos de um festival possuem diferentes impactos na experiência dos visitantes, em sua satisfação e intenção de revisitar.

Além da intenção da revisitar, a satisfação também pode promover o engajamento do participante em mídias sociais, visto que, os consumidores são engajados quando se sentem motivados pela marca a se envolverem, ou seja, encontram-se satisfeitos com esta (ZailskaiteJakste \& Kuvykaite, 2012; Bryce, Curran, O'Gorman, \& Taheri, 2015; Hollebeek, Juric, \& Tang, 2017). Todavia, surpreendentemente pouca atenção tem sido dada para estudos que relacionem o engajamento e a satisfação dos visitantes de festivais (Organ, Koenig-Lewis, Palmer, \& Probert, 2015). O engajamento pode ser medido através de 5 "ações", propostas pelos autores Zailskaite-Jakste \& Kuvykaite, (2012), baseado nos estudos de Owyang \& Lovett (2010), as quais são representadas por: "Assistir", "Compartilhamento", "Comentando", "Produção" e "Defender".

Para os autores, a primeira etapa do engajamento é quando os consumidores ainda estão observando a marca, e esse momento é essencial para o aumento de reconhecimento. Normalmente é por meio de um conteúdo de mídia social virtual adequadamente produzido que os consumidores se interessam, e este precisa atender às necessidades. Se a marca se comunica adequadamente, ou seja, se o conteúdo relacionado à marca é interessante, atraente, fornece valor, pode ser avaliado observando o comportamento do consumidor, ou seja, através do que seriam o segundo e terceiro estágio, o engajamento do consumidor nas mídias sociais virtuais. $\mathrm{Na}$ quarta etapa, os consumidores se engajam e produzem e compartilham o conteúdo produzido, que está vinculado a marcas específicas. Nesse estágio, pode-se observar quais consumidores se tornam fiéis (Zailskaite-Jakste \& Kuvykaite, 2012).

Porém, o engajamento online também pode ser medido por outras vertentes, quando se trata de Práticas de envolvimento da comunidade de marca virtual - VBCEP, os autores Hollebeek, Juric e Tang (2017) desenvolvem uma tipologia de oito componentes que refinam o modelo de quatro componentes das práticas de engajamento da comunidade da marca proposto por Schau, Muñiz Jr e Arnould (2009). O modelo compreende "cumprimentar”, "regular”, “assistir”, “celebrar”, “apreciar”, “simpatizar”, “misturar” e “classificar”. Essas práticas contribuem e mantêm a visão e a identidade da comunidade e fortalecem a consciência 
Kraus, C. B., Fiuza, T. F., Zucco, F. D., \& Quadros, C. M. B. (2020). Satisfação e engajamento de visitantes à festivais: análise empírica de uma Oktoberfest

compartilhada da comunidade. Para essa pesquisa, optou-se por utilizar cinco ações que as autoras do presente estudo julgaram melhor representar as ações do engajamento online para alcançar os objetivos propostos, estas foram: Curtir, Comentar, Compartilhar, Assistir e Defender, utilizando as teorias dos autores: Zailskaite-Jakste; Kuvykaite (2012) e Hollebeek, Juric e Tang (2017).

As plataformas online (ou seja, sites e mídias sociais) das organizações de gestão de destinos (DMOs) estão entre as ferramentas mais úteis para a construção e promoção de uma imagem de destino (DI) (Molinillo, Liébana-Cabanillas, Anaya-Sánchez \& Buhalis, 2018). O engajamento é muitas vezes determinado pelo contexto (Black, 2005; Brodie, Hollebeek, Jurić \& Ilić, 2013; Higgins \& Scholer, 2009). De acordo com Taheri, Jafari e O'Gorman. (2014), as definições de engajamento incluem qualidades de apego, conexão emocional, compromisso e devoção. Do ponto de vista do marketing, o conceito é interativo e variável de contexto (Hollebeek, 2011). Existe uma relação positiva entre o engajamento crescente e a satisfação das experiências de consumo entre os consumidores (Brodie et. al., 2011; Higgins \& Scholer, 2009), que é afetada por variância significativa no nível de engajamento entre os consumidores (Brodie et al., 2013; Hollebeek, 2012).

A extensão do envolvimento pode ser influenciada por níveis de conhecimento (Hollebeek, 2012), motivação (Brodie et al., 2013) e freqüência de consumo (Mollen; Wilson, 2010). Os níveis elevados de motivações múltiplas demonstraram ter impacto sobre o compromisso e o envolvimento com ofertas de serviços (Kumar, Aksoy, Donkers, Venkatesan, Wiesel \& Tillmanns, 2010; Siu, Zhang, Dong \& Kwan, 2013; Taheri et al., 2014; Van Doorn, Lemon, Mittal, Nass, Pick, Pirner \& Verhoef, 2010), enquanto os níveis de conhecimento do consumidor demonstraram afetar a lealdade e o engajamento no comportamento do consumo (Baloglu, 2001; Ho, Lin \& Chen, 2012). O envolvimento do consumidor difere do envolvimento do consumidor. Onde o envolvimento pertence ao interesse do consumidor em um produto ou serviço, o engajamento sugere um nível mais profundo de compromisso e interesse em um relacionamento bidirecional dentro de um mercado (Abdul-Ghani; Hyde; Marshall, 2011).

Pesquisas relacionadas a temáticas são mais comuns nos estudos sobre as mídias sociais e o comportamento do consumidor em jogos (Zailskaite-Jakste \& Kuvykaite, 2012; Jensen et al., 2016; Lu \& Seah, 2018) e na administração de empresas e organizações (White \& Menzel, 2015; Andriof, Waddock, Husted, \& Rahman, 2017). No turismo, trabalhos sobre engajamento 
Kraus, C. B., Fiuza, T. F., Zucco, F. D., \& Quadros, C. M. B. (2020). Satisfação e engajamento de visitantes à festivais: análise empírica de uma Oktoberfest

são mais relacionados ao segmento cultural (Taheri, Jafari e O'Gorman, 2014; Bryce et al., 2015) e serviços turísticos (Yeh, 2013; So, Kinng, \& Sparks, 2014). Os estudos empíricos que trabalham diretamente o engajamento em festivais ainda são incipientes na literatura (Organ et al., 2015).

Segundo Taheri et al. (2014), as definições de engajamento incluem qualidades de apego, conexão emocional, comprometimento e devoção. O processo de formação desse aspecto é revelado através da interação entre o consumidor e a marca (Zailskaite-Jakste \& Kuvykaite, 2012). Dentro de tal perspectiva, Yeh (2013) defende que um turista possui maior propensão de sentir-se satisfeito e encorajado a retornar ao destino caso este possua um nível significativo de engajamento com o local. Esse exposto é corroborado no estudo de So et al. (2014) os quais perceberam que o engajamento é percebido nas empresas de serviços turísticos em cinco níveis: identificação, entusiasmo, atenção, absorção e interação. E após a percepção destes, o consumidor tende a possuir uma imagem mais positiva da empresa e ainda, apresentar maiores índices de fidelidade a organização (So et al., 2014).

Dentro da perspectiva dos festivais, Organ et al. (2015) buscou investigar dentre outros aspectos, as relações entre o engajamento dos visitantes de um festival de alimentos com a intenção comportamental (futura e imediata), as emoções positivas e negativas, e por fim, a satisfação dos frequentadores. Os resultados do estudo demonstraram a importância do engajamento, visto que maiores níveis deste apenas não influenciaram significativamente as emoções negativas dos participantes. O restante dos aspectos relacionados ao festival (acima citados), foram significativamente influenciados pelo engajamento dos visitantes, tanto logo após a realização do festival, como também seis meses após a realização deste.

Evidencia-se assim, que apesar de pouco inserido - de forma direta - na literatura dos festivais, o engajamento é um fator crucial para o desenvolvimento e consolidação de tal segmento de evento. Taheri et al. (2014) defendem em sua pesquisa que o engajamento inclui elementos cognitivos, emocionais e/ou comportamentais os quais são capazes de influenciar, dentre outros aspectos, na satisfação e lealdade do visitante. Com base na literatura existente, percebe-se então a relevância de avaliar o engajamento e a satisfação de forma conjunta em pesquisas, buscando assim, ampliar os níveis de compreensão do comportamento do consumidor em festivais. 
Kraus, C. B., Fiuza, T. F., Zucco, F. D., \& Quadros, C. M. B. (2020). Satisfação e engajamento de visitantes à festivais: análise empírica de uma Oktoberfest

\section{Metodologia}

A presente pesquisa fez parte do pré-teste de dissertação de uma das autoras e, foi construída com o intuito de analisar a relação entre a satisfação e o engajamento online na participação do visitante da Oktoberfest de Blumenau, Santa Catarina, Brasil. Desta forma, caracterizou-a como exploratória, documental e descritiva, elaborada através de uma abordagem quantitativa. Foi utilizado um levantamento survey cujo objetivo é a obtenção de dados e informações sobre as características ou opiniões de determinados grupos.

Para a seleção da amostragem, optou-se pelo método não probabilístico por conveniência. Para o levantamento de dados da pesquisa, seguiu-se o método de questionário semi-estruturado, autopreenchível, com perguntas fechadas e uma aberta, o que permite respostas mais precisas com base em escalas e medidas numéricas. O questionário foi estruturado em três blocos, sendo o primeiro destinado a satisfação, o segundo ao engajamento online e por fim, caracterização sociodemográfica dos visitantes.

A escala de satisfação dos visitantes, foi baseada no estudo de Moretti et al. (2016) de onde foram adaptadas 16 afirmações divididas em 5 dimensões: segurança, empatia, confiabilidade, atendimento e tangibilidade. As variáveis pertencentes a satisfação, foram medidas através da escala Likert de cinco itens, partindo de 1 (totalmente insatisfeito) até 5 (totalmente satisfeito).

Para medir o engajamento online utilizou-se como base o estudo de Zailskaite-Jakste e Kuvykaite (2012) e Hollebeek et al., (2013), dentre as ações que os autores descrevem como sendo as principais do engajamento, optou-se por escolher apenas 5 (cinco) delas. Foram escolhidas as que melhor se enquadravam para a realidade do presente trabalho, sendo elas: Curtir, Comentar, Compartilhar, Acompanhar e Defender. Para verificar a propensão dos respondentes em realizar cada uma dessas ações que envolvem o engajamento, criou-se 5 situações/frases relacionadas a festa e cada uma delas virou uma dimensão. Essas dimensões foram criadas para facilitar tanto o entendimento dos respondentes, inserindo-os em um contexto para falar acerca de engajamento, quanto para o processo de análise, estas foram chamadas de: informação, experiência, status, amizade e novidade, as dimensões foram criadas pelos pesquisadores. O engajamento foi medido por meio de uma escala de quatro pontos, sendo 1 - nunca, 2 - raramente, 3 - às vezes e 4 - sempre foi utilizada para mensurar tal constructo.

A coleta de dados da pesquisa ocorreu no mês de outubro de 2017, durante a $34^{\text {a }}$ Oktoberfest Blumenau. A coleta de dados ocorreu durante oito dias de festa, e resultou em 279 
Kraus, C. B., Fiuza, T. F., Zucco, F. D., \& Quadros, C. M. B. (2020). Satisfação e engajamento de visitantes à festivais: análise empírica de uma Oktoberfest

questionários respondidos. Todavia, 64 questionários foram excluídos da pesquisa por estarem incompletos ou rasurados. Desta forma, a amostra final foi composta por 215 questionários válidos.

Para realizar a análise dos resultados alcançados e verificar a confiabilidade e consistência interna dos constructos, utilizou-se o Software Microsoft Excel® 2016 para a codificação e tabulação dos dados coletados e para os tratamentos estatísticos, os dados foram obtidos através do pacote estatístico Statistical Package for the Social Sciences ${ }^{\circledR} 22$ (SPSS). As análises descritivas foram demonstradas através de análise descritiva (frequências e porcentagens) e ainda, comparação de médias. Já os dados multivariados foram dispostos por Regressão Linear.

\section{Caracterização da amostra da pesquisa}

Por meio dos dados sociodemográficos coletados através do instrumento de coleta de dados, foi possível traçar o perfil do respondente que frequentou a Oktoberfest em 2017. Vale ressaltar que a amostra compreende 215 questionários válidos coletados durante o festival. A Tabela 1 destaca as variáveis sociodemográficas e o perfil dos entrevistados, divididos em gênero, estado civil, classe econômica, faixa etária, ocupação profissional e formação escolar.

Tabela 1 - Caraterística da amostra

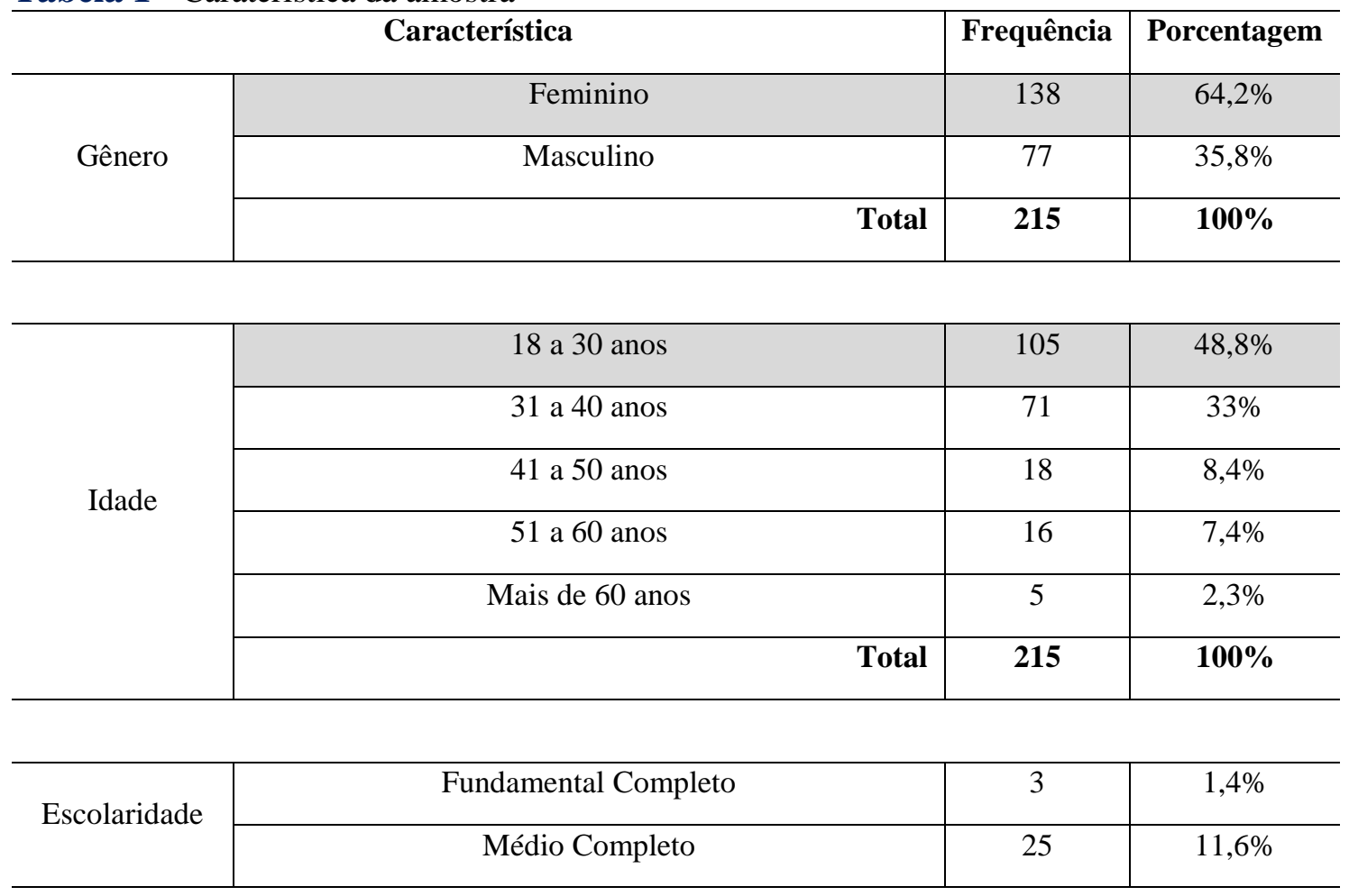


Kraus, C. B., Fiuza, T. F., Zucco, F. D., \& Quadros, C. M. B. (2020). Satisfação e engajamento de visitantes à festivais: análise empírica de uma Oktoberfest

\begin{tabular}{|c|c|c|c|}
\hline \multicolumn{2}{|r|}{ Característica } & \multirow{2}{*}{$\begin{array}{c}\text { Frequência } \\
37\end{array}$} & \multirow{2}{*}{$\begin{array}{c}\text { Porcentagem } \\
17,2 \%\end{array}$} \\
\hline & Superior Incompleto & & \\
\hline & Superior Completo & 65 & $30,2 \%$ \\
\hline & Pós-Graduação Incompleta & 23 & $10,7 \%$ \\
\hline & Pós-Graduação Completa & 62 & $28,8 \%$ \\
\hline & Total & 215 & $100 \%$ \\
\hline \multirow{8}{*}{$\begin{array}{c}\text { Ocupação } \\
\text { Profissional }\end{array}$} & Não trabalho/desempregado & 18 & $8,4 \%$ \\
\hline & Funcionário Público & 41 & $19,1 \%$ \\
\hline & Empregado Assalariado & 72 & $33,5 \%$ \\
\hline & Conta própria ou autônomo & 24 & $11,2 \%$ \\
\hline & Empresário & 24 & $11,2 \%$ \\
\hline & Estagiário/Estudante & 25 & $11,6 \%$ \\
\hline & Aposentado & 11 & $5,1 \%$ \\
\hline & Total & 215 & $100 \%$ \\
\hline
\end{tabular}

\begin{tabular}{c|c|c|c}
\hline \multirow{4}{*}{ Faixa salarial } & Até $\mathrm{R} \$ 937,00$ & 3 & $1,4 \%$ \\
\cline { 2 - 4 } & De $\mathrm{R} \$ 937,00$ até $\mathrm{R} \$ 2.811,00$ & 29 & $13,5 \%$ \\
\cline { 2 - 4 } & De $\mathrm{R} \$ 2811,00$ até $\mathrm{R} \$ 5.622,00$ & 45 & $20,9 \%$ \\
\cline { 2 - 4 } & De R $\$ 5.622,00$ até $\mathrm{R} \$ 8.433,00$ & 43 & $20 \%$ \\
\cline { 2 - 4 } & De R $\$ 8.433,00$ até $\mathrm{R} \$ 14.055,00$ & 35 & $16,3 \%$ \\
\cline { 2 - 4 } & Mais de $\mathrm{R} \$ 14.055,00$ & 36 & $16,7 \%$ \\
\cline { 2 - 4 } & Prefiro não responder & $\mathbf{2 1 5}$ & $\mathbf{1 0 0 \%}$ \\
\hline
\end{tabular}

\begin{tabular}{l|c|c|c}
\hline \multirow{2}{*}{} & Blumenau & 55 & $26 \%$ \\
\cline { 2 - 4 } & Sul & 76 & $35 \%$ \\
\cline { 2 - 4 } & Centro-Oeste & 16 & $3,335 \%$ \\
\cline { 2 - 4 } \begin{tabular}{l} 
Região de \\
\cline { 2 - 4 }
\end{tabular} & Sudeste & 60 & $28 \%$ \\
\cline { 2 - 4 } & Norte & 2 & $0,665 \%$ \\
\cline { 2 - 4 } & Nordeste & 14 & $7 \%$ \\
\cline { 2 - 4 } & & $\mathbf{2 1 5}$ & $\mathbf{1 0 0 \%}$ \\
\hline
\end{tabular}

Fonte: Dados da pesquisa (2017). 
Kraus, C. B., Fiuza, T. F., Zucco, F. D., \& Quadros, C. M. B. (2020). Satisfação e engajamento de visitantes à festivais: análise empírica de uma Oktoberfest

Destaca-se que a amostra foi composta em sua maioria de mulheres $(64,2 \%)$, com idade entre 18 e 30 anos (48,8\%), com ensino superior completo (30,2\%), empregados assalariados (33,5\%), com renda predominante de $\mathrm{R} \$ 2.811,00$ até $\mathrm{R} \$ 5.622,00$ reais e de $\mathrm{R} \$ 5.622,00$ até $\mathrm{R} \$ 8.433,00$. A região que teve mais participação foi a região sul (35\%) e Sudeste (28\%). Além das características demográficas dos participantes, o instrumento de coleta de dados buscava também identificar os hábitos de visita e consumo da Oktoberfest. Esta etapa buscava averiguar a forma de acompanhamento do participante, o número de vezes que participou do festival, se utiliza redes sociais e por fim, a frequência de utilização. Em relação ao acompanhamento, a maioria dos inqueridos afirmaram visitar a Oktoberfest em casal (44,2\%), em mais de quatro pessoas $(21,4 \%)$ ou em um grupo formado por até quatro pessoas $(14,4 \%) .13 \%$ afirmaram estar sozinhos e por fim, 7\% estavam acompanhados da família.

Dos 215 inqueridos, apenas 2,8\% estavam visitando a Oktoberfest pela primeira vez, indicando que a ampla maioria dos inqueridos eram frequentadores repetidos. As maiores frequências de respostas foram dos indivíduos que participavam do festival pela segunda vez $(36,3 \%)$ ou entre três ou cinco vezes $(27,9 \%)$. Destaca-se ainda, que uma taxa significativa de respostas compreendeu também entre 6 a 9 edições e mais de dez edições, com 22,3\% e 10,7\%, respectivamente. Como pode-se perceber, a maior parte dos respondentes já esteve no evento em anos anteriores, esse dado retrata a importância e relevância que o evento tem para a cidade e como isso pode trazer benefícios ao destino, pois de acordo com Getz (2008) a visita repetida aos festivais tem implicações mais amplas para o marketing local, pois os visitantes conhecem a cidade por meio do festival e posteriormente podem optar por retornar a cidade.

Assim, como esperado, a ampla maioria dos respondentes utilizava rede social $(98,6 \%)$, onde apenas 3 participantes afirmaram não utilizar tal ferramenta (1,4\%). Também como já previsto, uma parcela considerável dos inqueridos $(87,9 \%)$ utilizam redes sociais todos os dias, mais de uma vez por dia, 4,7\% afirmaram utilizar uma vez por dia e seis participantes utilizam duas ou três vezes por semana. As menores percentagens alcançadas foram aquelas relacionadas a utilização de redes sociais uma vez por semana e três vezes por semana com 1,9\% e 0,5\%, respectivamente. Destaca-se que as redes sociais mais utilizadas são o Whatsapp (93,5\%), Facebook (90,7\%) e Instagram (73\%).

O resultado já era esperado, pois atualmente o Instagram e o Facebook são as duas maiores plataformas de compartilhamento de conteúdo online, enquanto o Whatsapp é considerado o maior aplicativo de mensagens instantâneas. Até o momento em 2018, o 
Kraus, C. B., Fiuza, T. F., Zucco, F. D., \& Quadros, C. M. B. (2020). Satisfação e engajamento de visitantes à festivais: análise empírica de uma Oktoberfest

Facebook possui 2,3 bilhões de usuários (O Globo, 2018), o Instagram 800 milhões de usuários (Instagram, 2018) e o Whatsapp possui 1.5 bilhões de usuários (BBC, 2018).

\section{Comparação das médias dos constructos}

Para compreender melhor os hábitos de engajamento online e níveis de satisfação dos visitantes da Oktoberfest, realizou-se um cruzamento de médias para identificar se há diferenças entre gênero. Os dados deste cruzamento são expostos na Tabela 2.

Tabela 2 - Cruzamento de dados: Gênero X Dimensões do estudo

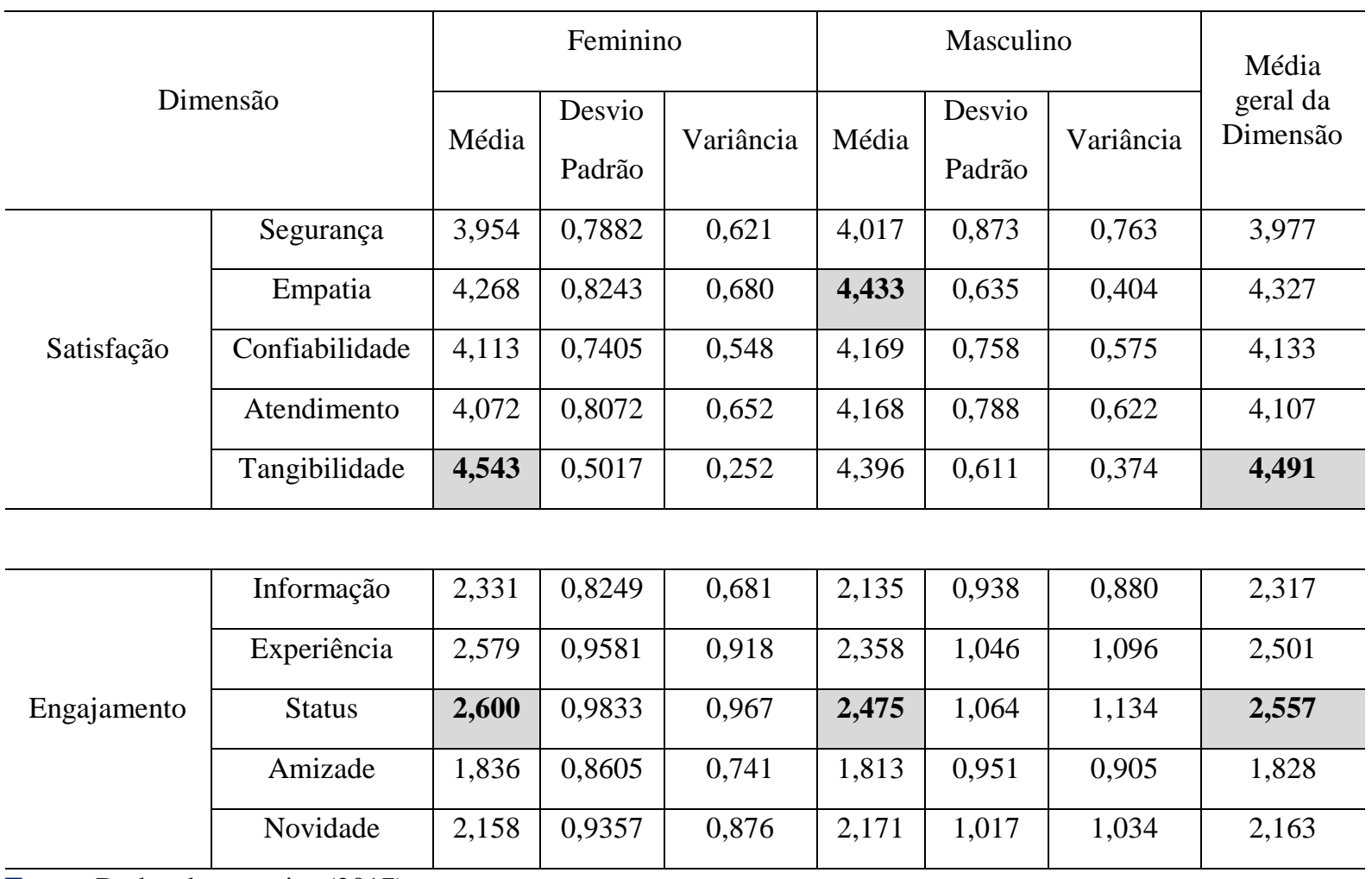

Fonte: Dados da pesquisa (2017).

Como pode-se perceber na Tabela 2, existe uma diferença de comportamento entre homens e mulheres quando se trata da satisfação em relação à Oktoberfest Blumenau. Os homens ficaram mais satisfeitos com a dimensão Empatia, ou seja, tudo que envolve a consideração e atenção individualizada no atendimento aos clientes. Já as mulheres, se demonstraram mais satisfeitas com a Tangibilidade do evento, cujos aspectos representam a aparência do local, equipamentos, pessoal e material de comunicação. Em relação as outras dimensões, apesar de pouca diferença entre as médias, percebem-se que os homens ficaram 
Kraus, C. B., Fiuza, T. F., Zucco, F. D., \& Quadros, C. M. B. (2020). Satisfação e engajamento de visitantes à festivais: análise empírica de uma Oktoberfest

mais satisfeitos do que as mulheres. Os dados encontrados na pesquisa foram ao encontro dos encontrados por Moretti et al., (2016) em quase todas as dimensões, no estudo dos autores o destaque ficou com a dimensão Tangibilidade, seguida da Empatia. Iguais aos dados encontrados nesta pesquisa, realizada na mesma festa, porém seis anos depois. Com isso, é possível perceber que a qualidade do evento se manteve no decorrer dos anos.

Quando se trata do engajamento online, é possível perceber o contrário, em quase todas as dimensões, apesar de pouca diferença entre as médias, as mulheres se demonstraram mais engajadas online do que os homens, exceto na dimensão Novidade, que envolve o interesse do respondente em buscar informações sobre o mundo cervejeiro nas redes sociais. A dimensão Status foi a média com maior destaque em ambos os gêneros, representando que tanto homens quanto mulheres tem maior probabilidade de se engajar online quando se trata de postagens de fotos e vídeos nas redes sociais. A dimensão Experiência, segunda maior média de engajamento é uma que deve chamar atenção dos organizadores da Oktoberfest, pois de acordo com dados divulgados pelo relatório do Sebrae (2018), o mercado de turismo de negócios e eventos é competitivo e, para se destacar, é preciso investir em criatividade e diferenciação. Fica evidente que os turistas, mesmo em viagens de negócios, estão em busca de experiências.

Através dos resultados apresentados na pesquisa, pode-se também identificar quais são os assuntos que os visitantes tendem a interagir de maneira mais significativa nas mídias sociais. As cinco ações de engajamento, criadas pelos autores, evidenciam a necessidade de compreender como as empresas podem promover o engajamento do consumidor e consequentemente, melhorar a sua marca. Desta forma, observar e conhecer quais são seus principais consumidores buscando prever adequadamente a interação destes é fundamental, visto que a literatura já evidenciou que os consumidores se engajam quando são motivados criativamente pela marca a se envolverem, sentirem-se incentivados por outros consumidores ou ainda, receber determinados benefícios para a comunicação ativa nas plataformas de opinião. Neste sentido, Zailskaite-Jakste e Kuvykaite (2012) defendem que ações de engajamento do consumidor em mídias sociais devem ser associadas aos estágios de desenvolvimento deste nas mídias sociais, ou seja, assistir, compartilhar, comentar, produzir ou defender. 


\section{Correlação de Spearman}

Para verificar as correlações entre as variáveis do estudo, utilizou-se o coeficiente de Spearman para medir a intensidade entre as variáveis ordinais, ou seja, o construto versus as características sociodemográficas dos entrevistados. As determinações de valores, de acordo com Hair Jr., Black, Babin, Anderson \& Tatham (2009), junto a cada correlação, apresentamse o nível de significância estatística, que segundo os autores, quanto menor o índice mais verdadeiro são os resultados matemáticos:

Quadro 1 - Determinação de Valores

\begin{tabular}{|l|l|}
\hline \multicolumn{1}{|c|}{ Coeficiente de Spearman } & \multicolumn{1}{c|}{ Significância Estatística } \\
\hline a) correlação leve, quase imperceptível $(0,01$ a & a) $>0,05$ - Não significante \\
$0,20)$; & b) 0,01 a 0,05 - Significante \\
b) correlação pequena, mas definida $(0,21$ a 0,40$) ;$ & c) 0,001 a 0,01 - Muito Significante \\
c) correlação moderada $(0,41$ a 0,70$) ;$ & d) $<0,001$ - Extremamente Significante \\
d) alta correlação $(0,71$ a 0,90$) ;$ & \\
e) correlação muito forte $(0,91$ a 1,00$)$. & \\
\hline
\end{tabular}

Fonte: Hair Jr. et al. (2009).

A Tabela 3 apresenta os valores encontrados com as correlações entre o construto de Satisfação e as variáveis sociodemográficas dos pesquisados. Conforme dados destacados na Tabela 3, as correlações significativas encontradas entre as dimensões do estudo, com o perfil sociodemográfico dos pesquisados tiveram índices de correlação leves, quase imperceptíveis (Escolaridade com Informação; Ocupação com Tangibilidade; Escolaridade com Status) e alguns alcançaram índices de correlação pequenas, mas definidas (Ocupação com Novidade; Idade com Amizade; Escolaridade com Experiência; Ocupação com Experiência).

Tabela 3 - Correlação de Spearman: Dimensões de estudo X característica da amostra

\begin{tabular}{|c|c|c|c|c|c|c|c|c|}
\hline \multirow{2}{*}{ Dimensão } & \multicolumn{2}{|c|}{ Idade } & \multicolumn{2}{|c|}{ Escolaridade } & \multicolumn{2}{|c|}{ Ocupação } & \multicolumn{2}{|c|}{ Salário } \\
\hline & Correlação & Sig. & Correlação & Sig. & Correlação & Sig. & Correlação & Sig. \\
\hline \multicolumn{9}{|c|}{ Engajamento } \\
\hline Informação & $-0,062$ & 0,367 & $-0,191 * *$ & 0,005 & 0,073 & 0,286 & $-0,021$ & 0,763 \\
\hline Experiência & 0,024 & 0,73 & $-0,227 * *$ & 0,001 & $0,238 * *$ & 0,000 & $-0,044$ & 0,517 \\
\hline Status & $-0,088$ & 0,2 & $-0,165^{*}$ & 0,015 & 0,097 & 0,155 & $-0,015$ & 0,824 \\
\hline Amizade &,$- 215 * *$ & 0,002 & $-0,076$ & 0,267 & 0,106 & 0,123 & 0,035 & 0,611 \\
\hline Novidade & $-0,008$ & 0,907 & $-0,055$ & 0,421 & $0,206 * *$ & 0,002 & $-0,005$ & 0,941 \\
\hline \multicolumn{9}{|c|}{ Satisfação } \\
\hline Segurança & 0,02 & 0,766 & 0,117 & 0,087 & $-0,007$ & 0,917 & $-0,069$ & 0,313 \\
\hline Empatia & 0,052 & 0,447 & 0,091 & 0,186 & 0,028 & 0,686 & $-0,067$ & 0,329 \\
\hline Confiabilidade & 0,015 & 0,822 & 0,062 & 0,362 & 0,097 & 0,155 & $-0,016$ & 0,821 \\
\hline
\end{tabular}


Kraus, C. B., Fiuza, T. F., Zucco, F. D., \& Quadros, C. M. B. (2020). Satisfação e engajamento de visitantes à festivais: análise empírica de uma Oktoberfest

\begin{tabular}{|c|c|c|c|c|c|c|c|c|}
\hline Atendimento & 0,005 & 0,941 & 0,039 & 0,573 & 0,079 & 0,249 & $-0,082$ & 0,233 \\
\hline Tangibilidade & 0,06 & 0,38 & $-0,021$ & 0,754 & $0,163^{*}$ & 0,017 & $-0,048$ & 0,48 \\
\hline
\end{tabular}

Fonte: Dados da pesquisa (2017).

Os resultados podem indicar que o nível de escolaridade dos respondentes pode influenciar no quanto estão dispostos a reagir às informações disponíveis sobre a Oktoberfest nas mídias sociais virtuais. O mesmo ocorre quando se trata da "vontade" do respondente em postar fotos e vídeos seus e de amigos durante a Oktoberfest nas redes sociais virtuais, ou seja, dependendo do nível de escolaridade do respondente, ele pode estar ou não, propenso à essas atitudes online. Já quando se trata da ocupação profissional, esta se correlaciona apenas quando se trata da escolha de lanches, cervejas e o gosto em relação às atrações musicais da festa.

Porém, dentre as correlações pequenas, destaca-se que os resultados podem indicar que a Ocupação profissional dos respondentes está correlacionada com a vontade que a pessoa tem em ficar por dentro das novidades cervejeiras, estando mais disposta a interagir com esse tipo de publicação online. Já a idade está correlacionada com a amizade, demonstrando que determinadas faixas etárias estão mais propensas a interagir de forma online com a festa quando a intenção é conhecer e encontrar pessoas na Oktoberfest. Pode-se perceber também que a escolaridade dos respondentes possui correlação com a experiência, demonstrando que, dependendo do nível de escolaridade a pessoa está mais ou menos propensa a publicar suas experiências vividas na Oktobefest online. Por fim, a ocupação profissional também pode indicar o quão disposto(a) a pessoa está de divulgar suas experiências vividas na Oktoberfest.

\section{Regressão linear}

Inicialmente utilizou-se o Alpha de Cronbach para verificar a confiabilidade dos construtos utilizados. Conhecido como indicador de veracidade dos dados, o Alpha verifica o grau de concordância dos respondentes em relação a um construto teórico aplicado. Sendo assim, os índices superiores a 0,60 são considerados aceitáveis para validação da convergência interna da dimensão (Cronbach, 1951). Destaca-se que o escore geral da pesquisa foi de 0,937, também foi feito o Alpha separado de cada um dos constructos, que atingiram os índices de 0,898 (Satisfação) e 0,960 (Engajamento), considerados escores ótimos para dar continuidade às análises estatísticas. 
A Regressão Linear é a análise de relação que responde uma pergunta, como por exemplo: “quanto Y irá mudar, se X mudar?”, ou seja, se X mudar em determinado valor, podese ter uma estimativa do quanto Y mudará (Dancey \& Reidy, 2013). Em relação ao nível de significância estatística para Regressão Linear, Hair Jr et al. (2009) defendem que quanto menor o índice mais verdadeiro são os resultados matemáticos.

a) >0,05 - Não significante;

b) 0,01 a 0,05 - Significante;

c) 0,001 a 0,01 - Muito Significante;

d) $<0,001$ - Extremamente Significante;

Com o intuído de identificar possíveis relações entre as variáveis dependentes e os preditores, utilizou-se a Regressão Linear para verificar possíveis relações entre o constructo de Engajamento e Satisfação. Os dados demonstraram o valor de significância de 0,186, ou seja, não possui significância estatisticamente significativa $(\mathrm{p}<0,05)$. Obteve-se assim, como resultado da regressão, o $\mathrm{R}$ de 0,091 e $\mathrm{R}^{2}$ de 0,008. Estes resultados indicam que as variáveis apresentam 9,1\% de grau de associação e que $0,8 \%$ do engajamento depende da Satisfação.

O resultado também foi demonstrado de forma gráfica através do Gráfico 1 (extraído através do software SPSS). Por meio dos dados encontrados com a realização da Regressão Linear, foi possível perceber que o engajamento dos visitantes não depende da satisfação. Ou seja, não é porque o visitante está satisfeito que necessariamente ele irá compartilhar suas experiências na festa nas redes sociais, o mesmo ocorre entre os visitantes que se demonstraram menos satisfeitos, isso também não influenciou no engajamento online. 
Gráfico 1 - Regressão Linear: relações entre a satisfação e o engajamento da Oktoberfest

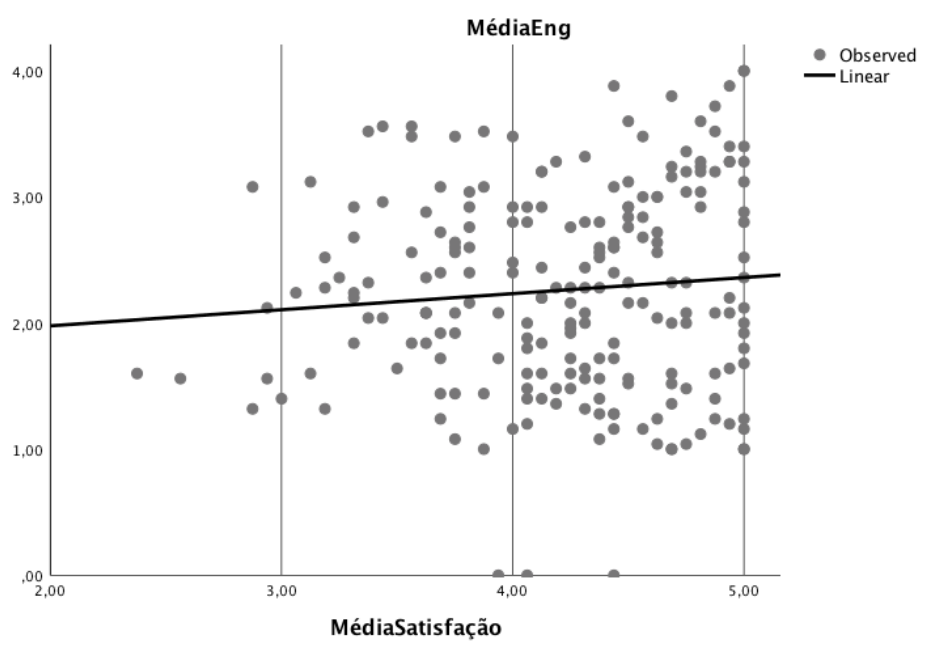

Fonte: Dados da Pesquisa (2017).

Achados relacionados foram encontrados pelas autoras Zucco e Kessler (2013), também através de um estudo sobre a Oktoberfest de Blumenau. Ao monitorar as redes sociais em 2012 para analisar se as mensagens postadas acerca do festival eram positivas ou negativas, as autoras perceberam que a maioria dos comentários eram positivos e verificaram um grande número de comentários e postagens acerca deste. Os bons resultados alcançados em tal ano, apontou o uso de redes sociais como decisão estratégica no complemento das campanhas de divulgação da Oktoberfest Blumenau. Os resultados da pesquisa de Zucco e Kessler (2013) evidenciaram ainda a relevância de verificar o engajamento online dos visitantes, devido ao fato que a postagem de um frequentador nas redes sociais não significa que esta seja positiva.

Os dados alcançados na presente pesquisa, acerca da Oktoberfest Blumenau, edição 2017, são de extrema relevância para a literatura relacionada ao turismo de eventos e festivais, principalmente devido ao fato da carência de estudos que relacionem festivais, satisfação e engajamento online (Organ et al., 2015). Apesar de haver pouca relação entre a satisfação e o engajamento online dos participantes, é importante destacar que, quanto mais satisfeito o participante ficar com o evento, maior a chance de recomendá-lo para outras pessoas. O estudo refere-se à indicação boca-a-boca, portanto, isso não significa que estariam dispostos a compartilhar experiências online acerca do evento, porém o fato de o visitante estar satisfeito com o festival pode fazer com que ele fale sobre o assunto com outras pessoas de forma offline. 
Kraus, C. B., Fiuza, T. F., Zucco, F. D., \& Quadros, C. M. B. (2020). Satisfação e engajamento de visitantes à festivais: análise empírica de uma Oktoberfest

O engajamento do consumidor nas mídias sociais está se tornando uma temática com profunda relevância, visto que, estas oferecem às empresas distintas oportunidades de ampliar sua notoriedade e interação com os seus consumidores. O uso de mídias sociais virtuais facilita na interatividade empresa x cliente, ou seja, oferece oportunidades de conversas e engajamento entre os envolvidos, ampliando a conscientização da marca e reforçando associações de marcas positivas e consequentemente, construção da lealdade do consumidor à marca (Zailskaite-Jakste \& Kuvykaite, 2012). Para eventos de grande porte, como a Oktoberfest Blumenau, é notável a importância dos visitantes se tornarem leais a marca do evento e até o momento, é possível perceber que os organizadores estão fazendo boas ações de marketing, pois a grande maioria dos visitantes desta edição já havia participado da festa em anos anteriores.

\section{Considerações finais}

Este estudo teve como objetivo analisar a relação entre a satisfação e o engajamento online dos visitantes da Oktoberfest Blumenau. Para responder ao objetivo, realizou-se um levantamento survey com questionário, aplicado com os visitantes da $34^{\mathrm{a}}$ Oktoberfest Blumenau, durante o mês de outubro, foram coletados 215 questionários válidos na pesquisa. A amostra foi composta em sua maioria por mulheres, com idade entre 18 e 30 anos, com ensino superior completo, empregados assalariados, com renda predominante de $\mathrm{R} \$ 2.811,00$ até $\mathrm{R} \$$ $5.622,00$ reais e a região de residência que teve mais participação foi a região sul. A maioria dos respondentes foi ao evento em casal e quase toda a amostra já havia participado de pelo menos duas edições da festa. Em relação às redes sociais, quase toda a amostra também utiliza algum tipo de rede social e entre as mais citadas estão Facebook, Instagram e o Whatsapp.

Por meio das médias foi possível identificar os diferentes comportamentos entre os gêneros dos respondentes, sendo que as mulheres se sentiram mais satisfeitas com a dimensão Tangibilidade, que envolve a aparência do local do evento, as pessoas que trabalham nele, equipamentos, etc. Enquanto os homens ficaram mais satisfeitos com a dimensão Empatia, ou seja, com a atenção individualizada no atendimento aos clientes. Já quando se trata de engajamento online, ambos os gêneros apontaram comportamentos semelhantes em quase todas as dimensões, sendo que a dimensão Status foi a com maior média entre elas para ambos.

Por meio da Regressão Linear foi possível verificar que o Engajamento dos visitantes não tem relação com a Satisfação, ou seja, não é porque o respondente está muito satisfeito que ele obrigatoriamente irá compartilhar informações sobre a Oktoberfest nas redes sociais. Os 
Kraus, C. B., Fiuza, T. F., Zucco, F. D., \& Quadros, C. M. B. (2020). Satisfação e engajamento de visitantes à festivais: análise empírica de uma Oktoberfest

dados encontrados no constructo de Satisfação se mostraram bastante semelhantes aos encontrados por Moretti et al. (2016) na edição de 2011 da festa. É importante destacar que a escala de pesquisa utilizada no presente estudo foi a proposta pelos autores por meio da Análise Fatorial, e a escala apresentou bons índices estatísticos para sua aplicação reduzida conforme proposto por eles.

Dentre os principais achados do estudo, destaca-se a análise do engajamento online voltado para o contexto de eventos e festivais, área esta ainda pouco explorada na literatura. Apesar de existirem alguns estudos na área, como os de Zailskaite-Jakste e Kuvykaite (2012), Bryce et al., (2015) e Hollebeek et al., (2017), estudos apenas teóricos, ou seja, vale ressaltar os bons índices estatísticos encontrados com a aplicação da escala de Engajamento em formato quantitativo. Conforme citado, alguns autores afirmam que a teoria não tem dado muita atenção para estudos que relacionam a satisfação e o engajamento online de seus participantes. Apesar de os índices de relação entre satisfação e engajamento online encontrados nesta pesquisa não tenham sido muito positivos, esse estudo pode ser o início de uma discussão sobre o tema.

Com os resultados alcançados na presente pesquisa, pode-se destacar as contribuições teóricas e gerenciais alcançadas ao final deste. No que se refere as contribuições teóricas, a pesquisa auxilia a literatura a compreender de maneira mais profunda as relações entre a satisfação dos visitantes de um festival cultural com o seu engajamento online, ou seja, a propagação de informações relacionadas a Oktoberfest em mídias sociais. Destaca-se que a realização de pesquisas relacionadas a festivais foi incentivada por autores como ZailskaiteJakste e Kuvykaite (2012), Bryce et al., (2015) e Hollebeek et al., (2017). O estudo fornece ainda, um maior conteúdo e aprofundamento teórico sobre a realização de Oktoberfests, o qual é destacado como necessário por Harrington et al. (2017) como necessário, visto que festivais culturais germânicos vem se propagando em nivel mundial, porém ainda permanecem pouco explorados na literatura.

Em relação as contribuições gerenciais, destaca-se principalmente o achado que a satisfação com o festival não possui uma relação direta e significativa com o engajamento online, ou seja, apenas o fato de estar satisfeito, não influencia no quanto o visitante gera conteúdo sobre a Oktoberfest. Assim, os gestores locais devem atentar-se aos dois aspectos e incentivar de maneira distinta tanto a satisfação quanto o engajamento e o incentivo em gerar informações online sobre o festival. Os resultados também evidenciam que o perfil sociodemográfico do visitante influencia na sua satisfação com as dimensões do evento, 
Kraus, C. B., Fiuza, T. F., Zucco, F. D., \& Quadros, C. M. B. (2020). Satisfação e engajamento de visitantes à festivais: análise empírica de uma Oktoberfest

necessitando uma analise continua para identificar pontos fortes e fracos gerais e específicos da Oktoberfest percebidos pelo seu público.

A realização da pesquisa contou com algumas limitações que geraram insights para próximos trabalhos. Como limitação de estudo destaca-se o baixo número da amostra, pois por se tratar de um evento festivo, onde as pessoas costumam ir para se divertir, beber e aproveitar a gastronomia alemã, muitas pessoas se recusaram a responder a pesquisa, prejudicando um pouco na hora de alcançar um número maior. Para estudos futuros, sugere-se a reaplicação da pesquisa com um público maior, para verificar os níveis estatísticos. Bem como uma pesquisa qualitativa para compreender melhor o porquê de não haver relação entre a satisfação dos visitantes com o engajamento nas redes sociais.

\section{Referências}

Abdul-Ghani, E., Hyde, K. F., \& Marshall, R. (2011). Emic and etic interpretations of engagement with a consumer-to-consumer online auction site. Journal of Business Research, 64(10), 1060-1066.

Andersson, T. D., Armbrecht, J., \& Lundberg, E. (2017). Linking event quality to economic impact: A study of quality, satisfaction, use value and expenditure at a music festival. Journal of Vacation Marketing, 23(2), 114-132.

Andriof, J., Waddock, S., Husted, B., \& Rahman, S. S. (2017). Unfolding stakeholder engagement. Unfolding stakeholder thinking, 26, 19-42.

Baloglu, S. (2001). Image variations of Turkey by familiarity index: Informational and experiential dimensions. Tourism management, 22(2), 127-133.

BBC. Como o Whatsapp ganha dinheiro? Recuperado 6 de junho de 2018 de: http://www.bbc.com/portuguese/geral-44009510.

Black, G. (2005). The engaging museum: Developing museums for visitor involvement. Psychology Press.

Blumenau. 34a edição da Oktoberfest foi de recordes de consumo e público. Recuperado 11 de abril de 2018 de: https://www.blumenau.sc.gov.br/secretarias/parque-vilagermanica/parque-vila-germanica/oktoberfest-2017-recebe-mais-de-568-mil-visitantes56.

Brodie, R. J., Hollebeek, L. D., Jurić, B., \& Ilić, A. (2011). Customer engagement: Conceptual domain, fundamental propositions, and implications for research. Journal of service research, 14(3), 252-271.

Bryce, D., Curran, R., O'Gorman, K., \& Taheri, B. (2015). Visitors' engagement and authenticity: Japanese heritage consumption. Tourism Management, 46, 571-581 
Kraus, C. B., Fiuza, T. F., Zucco, F. D., \& Quadros, C. M. B. (2020). Satisfação e engajamento de visitantes à festivais: análise empírica de uma Oktoberfest

Chen, W. C., Lee, C. F., \& Lin, L. Z. (2012). Investigating factors affecting festival quality: A case study of neimen song jiang jhen battle array, Taiwan. African Journal of Marketing Management, 4(2), 43-54.

Choo, H., Ahn, K., \& F. Petrick, J. (2016). An integrated model of festival revisit intentions: Theory of planned behavior and festival quality/satisfaction. International Journal of Contemporary Hospitality Management, 28(4), 818-838.

Christou, P., Sharpley, R., \& Farmaki, A. (2018). Exploring the Emotional Dimension of Visitors' Satisfaction at Cultural Events. Event Management, 22(2), 255-269

Cronbach, L. J. (1951). Coefficient alpha and the internal structure of tests. psychometrika, 16(3), 297-334.

Dancey, C. P., \& Reidy, J. (2013). Estatística sem matemática para psicologia. Penso Editora.

Deng, C. Q., Li, M., \& Shen, H. (2015). Developing a measurement scale for event image. Journal of Hospitality \& Tourism Research, 39(2), 245-270.

Egresi, I., \& Kara, F. (2014). Motives of tourists attending small-scale events: the case of three local festivals and events in Istanbul, Turkey. GeoJournal of Tourism and Geosites, 14(2), 93-110.

Esu, B. B., Arrey, V. M. E., Basil, G., \& Eyo, E. E. (2011). Analysis of the economic impacts of cultural festivals: the case of Calabar Carnival in Nigeria. Tourismos, 6(2).

Felsenstein, D., \& Fleischer, A. (2003). Local festivals and tourism promotion: The role of public assistance and visitor expenditure. Journal of Travel Research, 41(4), 385-392.

Getz, D. (2008). Event tourism: Definition, evolution, and research. Tourism management, 29(3), 403-428.

Getz, D., \& Page, S. J. (2016). Progress and prospects for event tourism research. Tourism Management, 52, 593-631.

Hair, J. F., Black, W. C., Babin, B. J., Anderson, R. E., \& Tatham, R. L. (2009). Análise multivariada de dados. Bookman editora.

Harrington, R. J., von Freyberg, B., Ottenbacher, M. C., \& Schmidt, L. (2017). The different effects of dis-satisfier, satisfier and delighter attributes: Implications for Oktoberfest and beer festivals. Tourism Management Perspectives, 24, 166-176.

Herrero, L. C., Sanz, J. Á., Bedate, A., \& del Barrio, M. J. (2012). Who pays more for a cultural festival, tourists or locals? A certainty analysis of a contingent valuation application. International Journal of Tourism Research, 14(5), 495-512. 
Kraus, C. B., Fiuza, T. F., Zucco, F. D., \& Quadros, C. M. B. (2020). Satisfação e engajamento de visitantes à festivais: análise empírica de uma Oktoberfest

Higgins, E. T., \& Scholer, A. A. (2009). Engaging the consumer: The science and art of the value creation process. Journal of Consumer Psychology, 19(2), 100-114.

Ho, C. I., Lin, M. H., \& Chen, H. M. (2012). Web users' behavioural patterns of tourism information search: From online to offline. Tourism Management, 33(6), 1468-1482.

Hollebeek, L. D. (2011). Demystifying customer brand engagement: Exploring the loyalty nexus. Journal of marketing management, 27(7-8), 785-807.

Hollebeek, L. D., Juric, B., \& Tang, W. (2017). Virtual Brand community engagement practices: a refined typology and model. Journal of Services Marketing, 31(3), 204-217.

Instagram. Sobre Nós. Recuperado 6 de junho de 2018 de: https://www.instagram.com/about/us/

Jensen, M. L., Lee, Y. H., Piercy, C. W., Dunbar, N. E., Elizondo, J., Bessarabova, E., ... \& Miller, C. (2016). Exploring failure and engagement in a complex digital training game: a multi-method examination. AIS Transactions on Human-Computer Interaction, 8(1), 1-20.

Kim, Y. H., Duncan, J., \& Chung, B. W. (2015). Involvement, satisfaction, perceived value, and revisit intention: A case study of a food festival. Journal of culinary science \& technology, 13(2), 133-158

Kumar, V., Aksoy, L., Donkers, B., Venkatesan, R., Wiesel, T., \& Tillmanns, S. (2010). Undervalued or overvalued customers: capturing total customer engagement value. Journal of service research, 13(3), 297-310.

Lu, Q. S., \& Seah, Z. Y. (2018). Social Media Influencers and Consumer Online Engagement Management. Digital Marketing and Consumer Engagement: Concepts, Methodologies, Tools, and Applications. 26, 1398-1406.

Manthiou, A., Lee, S. A., Tang, L. R., \& Chiang, L. (2014). The experience economy approach to festival marketing: Vivid memory and attendee loyalty. Journal of Services Marketing, 28(10), 22-35..

Mcdowall, S., Lillywhite, J. M., \& Simonsen, J. E. (2014). Renaissance ArtsFaire's Economic \& Socio-Cultural Impacts on a Local Community. Consortium Journal of Hospitality \& Tourism, 19(2).

Molinillo, S., Liébana-Cabanillas, F., Anaya-Sánchez, R., \& Buhalis, D. (2018). DMO online platforms: Image and intention to visit. Tourism management, 65, 116-130.

Moretti, S. L. A., Silva, C. C. B., Pinotti, R. de C., \& Zucco, F. D. (2016). Hospitalidade em festivais: avaliação comparada das Oktoberfest de Munique (RFA) e Blumenau (SC/Brasil). Revista Pasos, 14(1), 213. 
Kraus, C. B., Fiuza, T. F., Zucco, F. D., \& Quadros, C. M. B. (2020). Satisfação e engajamento de visitantes à festivais: análise empírica de uma Oktoberfest

Moretti, S. L. A., Zucco, F. D., \& Pozo, H. (2016). Motivações para visitar a Oktoberfest de Blumenau (BR) e Munique (RFA): uma análise comparativa utilizando a técnica Partial Least Squares. Revista Brasileira de Pesquisa em Turismo, 10(2), 374-393.

Moyano, C. A. M., Lengler, J. F. B., Angnes, D. L., \& Sampaio, F. V. (2015). Estratégia para fidelização do cliente em turismo: o caso de uma Oktoberfest no Brasil. Revista Turismo, Visão e Ação, 17(2), 387-413.

O GLOBO. Saiba como o Facebook se tornou um gigante de 2.3 bilhões de usuários. Recuperado 6 de junho de 2018 de: https://oglobo.globo.com/economia/saiba-comofacebook-se-tornou-umgigante-de-23-bilhoes-usuarios-22511806.

Organ, K., Koenig-Lewis, N., Palmer, A., \& Probert, J. (2015). Festivals as agents for behaviour change: A study of food festival engagement and subsequent food choices. Tourism Management, 48, 84-99

Parasuraman, A., Berry, L. L., \& Zeithaml, V. A. (1991). Refinement and reassessment of the SERVQUAL scale. Journal of retailing, 67(4), 420.

Parasuraman, A., Zeithaml, V. A., \& Berry, L. L. (1988). Servqual: A multiple-item scale for measuring consumer perc. Journal of retailing, 64(1), 12.

Robertson, M., Yeoman, I., \& Ali-knight, J. (2006). Gestão de festivais e eventos: uma perspectiva internacional de artes e cultura. Editora Roca.

Santos, T. dos, Zucco, F. D., \& Kraus, C. B. (2015). Imagem de eventos turísticos:

Perspectivas do Festival Brasileiro da Cerveja, Blumenau-SC. Turismo, Visão e Ação, 17(1), 128-149.

Sebrae. TURISMO DE NEGÓCIOS E EVENTOS (MICE). Recuperado 15 de junho de 2018 de: http://sis.sebrae-sc.com.br/produtos/relatorios-de-inteligencia/turismo-de-negocioseeventos-mice/5b22a05d06a0bf1800706124

Siu, N. Y. M., Zhang, T. J. F., Dong, P., \& Kwan, H. Y. (2013). New service bonds and customer value in customer relationship management: The case of museum visitors. Tourism Management, 36, 293-303.

Small, K. (2007). Social dimensions of community festivals: An application of factor analysis in the development of the social impact perception (SIP) scale. Event Management, 11(1-2), 45-55.

So, K. K. F., King, C., \& Sparks, B. (2014). Customer engagement with tourism brands: Scale development and validation. Journal of Hospitality \& Tourism Research, 38(3), 304-329.

Sohn, H. K., Lee, T. J., \& Yoon, Y. S. (2016). Relationship between perceived risk, evaluation, satisfaction, and behavioral intention: A case of local-festival visitors. Journal of Travel \& Tourism Marketing, 33(1), 28-45 
Kraus, C. B., Fiuza, T. F., Zucco, F. D., \& Quadros, C. M. B. (2020). Satisfação e engajamento de visitantes à festivais: análise empírica de uma Oktoberfest

Taheri, B., Jafari, A., \& O'Gorman, K. (2014). Keeping your audience: Presenting a visitor engagement scale. Tourism Management, 42, 321-329.

Tanford, S., \& Jung, S. (2017). Festival attributes and perceptions: A meta-analysis of relationships with satisfaction and loyalty. Tourism Management, 61, 209-220.

Tontini, G., Branco, L. L., Brandt, L. M. O., Ronchi, L., de Oliveira, P. R. V., \& Zanchett, R. (2018). Nonlinear antecedents of visitors' satisfaction with the oktoberfest in Brazil. Total Quality Management \& Business Excellence, 1-25

Van Doorn, J., Lemon, K. N., Mittal, V., Nass, S., Pick, D., Pirner, P., \& Verhoef, P. C. (2010). Customer engagement behavior: Theoretical foundations and research directions. Journal of service research, 13(3), 253-266.

White, J. D., \& Menzel, D. C. (2015). Citizen-Driven Administration: Civic Engagement in the United States Terry L. Cooper. The State of Public Administration, 22, 260-278.

Woosnam, K. M., \& Aleshinloye, K. D. (2018). Residents' emotional solidarity with tourists: Explaining perceived impacts of a cultural heritage festival. Journal of Hospitality \& Tourism Research, 42(4), 587-605.

Yeh, C. M. (2013). Tourism involvement, work engagement and job satisfaction among frontline hotel employees. Annals of Tourism Research, 42, 214-239.

Yoon, Y. S., Lee, J. S., \& Lee, C. K. (2010). Measuring festival quality and value affecting visitors' satisfaction and loyalty using a structural approach. International Journal of Hospitality Management, 29(2), 335-342

Zailskaite-Jakste, L., \& Kuvykaite, R. (2012). Consumer engagement in social media by building the brand. Proceedings in EIIC-1st Electronic International Interdisciplinary Conference, 1-15.

Zucco, F. D., \& Kessler, L. B. Monitoramento de resultados em mídias sociais no turismo: estudo da Oktoberfest Blumenau/SC 2012. In: X Seminário da Associação Nacional Pesquisa e Pós-Graduação em Turismo 15 a 18 de outubro de 2013 - Universidade de Caxias do Sul.

Zucco, F. D., Magalhães, M. D. R. A., \& Moretti, S. L. do A. (2010). Análise do nível de satisfação dos participantes: evidências das últimas três edições da Oktoberfest em Blumenau (2006, 2007 e 2008). Revisa Turismo, Visão e Ação, 12(3), 331-347. 